\title{
Navigating the Parent Involvement Terrain - The Engagement of High Poverty Parents in a Rural School District
}

\author{
Dwan V. Robinson \\ Lauren Volpé \\ College of Education, Ohio University \\ United States
}

\begin{abstract}
This research explored parents' perceptions of engagement experiences in the school life of their children. This qualitative study included a multi-site exploration of parents at two elementary public schools in an Appalachian school district. Participants for this inquiry included 16 high-poverty parents for the individual and focus group interviews. Parents were identified as high poverty based on their child's eligibility for free and reduced lunches under the U.S. National School Lunch Program. Interview protocols were designed to examine themes of school culture and climate, educational policy, and parental involvement. The research team collected interview transcripts from conversations with parents at the studied school sites. In examining data from the transcripts, several prominent themes emerged as findings. These findings included the fact that a) parents were motivated to be involved in schools; b) parents grappled with constraints limiting their time to be engaged in schools; and c) issues emerged suggesting that there were attitudes of in-group marginalization amongst parents in the schools. Recommendations are provided for educational leaders, teachers, and other school district personnel.
\end{abstract}

\section{Introduction}

High-poverty parents and families in rural communities continue to have truncated experiences in interacting with the school life of their children. Educator paradigms of parental involvement in schools typically align with the experiences of middle-class parents (Lareau, 2011). These traditional conceptions regarding the engagement of parents are considered ideals that are often not apparent to many parents 
in poverty and in rural contexts. While archetypal parental involvement models have improved the engagement of parents in many middle-class settings, rural and high poverty contexts warrant further contemplation about how to enrich the school-home bond. The changing demographics, diversity of families, and socio-economic backgrounds of students require educators, as Dewey $(1910,1916)$ notes, to be more reflective practitioners in order to serve students more effectively. Scholars and educators would be well served to strongly consider the varied situations and contexts where students and their families come from and what the implications might be for student achievement. Unfortunately, as theorists note (Harmon \& Schafft, 2009; Larson \& Howley, 2006), educators and parents in rural places have divergent views, and educational leaders have oftentimes considered parent expectations and interests as barriers to student advancement. Additionally, some school leaders perceive the rural context from a deficit perspective as wrought with challenges and issues as it relates to student advancement (Budge, 2006). In acknowledging the positive impact of parental involvement on student advancement, it is clear that new and innovative strategies are necessary in order to develop robust school and home relationships for rural, high poverty situations.

High-poverty parents and those in rural environments, like parents from various marginalized groups, can be reluctant to participate in school activities (Lightfoot, 2004). Similar to parents from underrepresented populations, high-poverty, rural parents are insecure about interacting with educational professionals because they perceive that they are not knowledgeable enough, articulate enough, or educated enough about the functioning of schools (Auerbach, 2012; Epstein, 2011). These parents are frequently uncertain and constrained about connecting with school personnel, how to access information about school affairs, and how to monitor student advancement (Horvat, Lareau \& Weininger, 2002; Lareau, 2003; McDermott \& Rothenburg, 2000). Without information regarding how schools operate and how to assess the progress of their children, parents are compromised in advocating for their children (Epstein, 2011).

On the other hand, educators too have uncertainty about how to engage highpoverty parents. Many times school initiatives are developed using traditional paradigms and ideas to involve parents, since many educator training programs prepare teachers using these approaches (McKenna \& Millen, 2013). Educator understandings of strategies for engaging parents are often not mindful of the needs of parents from vulnerable populations or cognizant of the assistance that parents from underrepresented groups can provide (Abrams \& Gibbs, 2002). School personnel in low-income contexts "tend to disregard parents' input as misguided or even ignorant" (p. 81). There continues to be a lack of understanding by all stakeholders and a void of research on the engagement experiences of high-poverty parents from rural communities in schools (Semke \& Sheridan, 2012). As such, it is difficult for educators to identify appropriate methods for involving and working with parents from underrepresented and high-poverty groups in schools (Epstein, 2011; Kroeger, 2014).

This study seeks to understand the perspectives of high-poverty, rural parents regarding involvement experiences in their children's schools. Additionally this research makes inquiry into how rural schools in high-poverty areas respond to federal and state mandates requiring "meaningful" (NCLB, 20 U.S.C. 6301, Sec. 1001 [12]) parental participation in school activities (as articulated by the No Child Left Behind Act). Specifically, we examined the efforts of two schools in the Appalachian region of the 
Navigating the Parent Involvement Terrain

United States. Data were collected through individual and focus-group interviews with parents to capture parental insights about their participation in the school lives of their children. As such, parents' engagement experiences are situated within the federal and state policy landscape, within perspectives on social and cultural capital, and within frameworks of effective family-school partnerships.

\section{Research Questions}

In light of the support for parental involvement from scholars, and policy encouragement regarding collaboration between parents and schools, this research endeavors to identify the engagement experiences and perceptions of parents in economically impoverished, rural communities. This study considered policies such as those provided by the No Child Left Behind Act (NCLB), Race to the Top, and state codes and regulations as guidance encouraging schools and districts to foster parental participation. Research questions for this study centered on the following: (1) How has a high-poverty, rural school district contextualized parent involvement in schools given federal and state policy encouragement? (2) How do parents perceive their experiences in engaging in the school life of their children? (3) What specific hindrances or opportunities might exist for parents to be engaged in the school life of their children?

\section{Conceptual and Theoretical Framework}

The foundation for this study relies on perspectives of parental involvement as informed by Epstein (2011), as well as theories of social networks and social and cultural capital as advanced by Bourdieu (1986), Lin (2001), Horvat, Lareau \& Weininger (2003), and Lareau (2011). Epstein (2011) provides a framework for parent/family engagement and the development of robust partnerships between schools, parents, and families. She suggests that educators must take proactive measures to strengthen school and home partnerships, and that educators need to be fully prepared to engage, involve, and interface with families of all kinds as they connect with schools. Further, Epstein purports that there are unlimited possibilities for improved understandings regarding parental involvement. She posits that there is a need for common interpretations regarding parent involvement between parents and educational leaders.

Bourdieu (1986) and Lin (2001) note that social capital theory embodies a system that involves the transfer of cultural capital or information and resources between and among individuals in varied social networks. These theorists illustrate that high-poverty parents can be positioned at various structural levels, and that there can be numerous levels of inequality or privilege depending on what the social ties and networks yield (Horvat et al., 2003, p. 345). Unlike middle-class parents, research shows that these underrepresented parental groups form tight bonds along the lines of kinship and affinity and tend not to interact with many parents (Horvat et al. 2003; Lin, 2000). Lin (2000) views relationships between kinship groups as social capital.

However, while many acknowledge that improvement is needed in the relationships between families and schools, a gap in ideas and relationships or a schoolcommunity divide exists: "The school-community divide is most severe in low-income and/or ethnic minority communities, where trust-building and communication processes 
are often compromised by social class and cultural differences" (Abrams \& Gibbs, 2000 p.81). Horvat et al. (2003) and Lareau (2000, 2011) posit that there are observable differences between how middle-class parents and high-poverty parents interact with schools. These theorists also acknowledge that schools operate under the framework of middle-class models of parent participation. These researchers suggest that the social networks between middle-class families enable them to access resources that advantage their children in schools, while high-poverty families lack access to similar supports. Furthermore, Lareau (2000) suggests that middle-class parents feel a sense of "entitlement" and are inclined to assume an activist posture as they interface with schools, while high-poverty parents are more compliant and "constrained" as it relates to issues with schools. Lareau $(2000,2011)$ also posits that high-poverty parents lack the cultural capital that can enhance their position and profile in schools. As such, highpoverty parents tend not to rock the boat when it comes to concerns about school affairs and perceive educational professionals as the authority regarding the schooling of their children (Abrams \& Gibbs, 2000; O’Connor, 2001). Parents from low-income and/or rural contexts often find themselves confused about the process for navigating school or district organizations and, as a consequence, they feel alienated or afraid to engage (Eccles \& Harold, 1996; Plunkett \& Bamaca-Gomez, 2003; Van Velsor \& Orozco, 2007).

Mandating engagement: A historical overview of legislation requiring family

involvement. Within the last 50plus years, federal and state educational policies have acknowledged the importance of meaningful school-parent partnerships to educational success. Title I of the Elementary and Secondary Education Act of 1965 (ESEA), for example, provides supplementary funding to public schools that serve a high percentage of students from low-income families. ESEA's funding is connected to the goal of closing the achievement gap between low-income students and their peers through school-wide or targeted assistance programs. In 2001, The United States Congress endeavored to reauthorize ESEA as the No Child Left Behind (NCLB) Act of 2001. Coupled with the encouragement for schools to institute regular assessments of student performance, Section 1118 of NCLB requires that schools, especially those receiving federal funding, develop policies and practices for actively including families in school activities, governance, and decision-making. Specifically, NCLB defines parental involvement as "the participation of parents in regular, two-way, and meaningful communication involving student academic learning and other school activities." Importantly, although NCLB suggests that parents should be treated as "full partners in their child's education," the mandate does not specify in detail what "meaningful communication" entails nor the extent to which schools should accommodate parents to ensure their participation. NCLB suggests the inclusion of parents as schools plan, implement, and evaluate school improvement initiatives (NCLB, 20 U.S.C. 6516. Sec. 1606.)

More recently, the executive and legis lative branches have augmented school improvement efforts by drafting and approving the Race to the Top legislation and School Improvement Grant policies. These resources have enabled states to target specific initiatives in school districts.

Federal education policy such as NCLB has helped to encourage action at the district and local levels of educational practice. The parent involvement guidelines 
Navigating the Parent Involvement Terrain

dictated by NCLB have been incorporated into state policies designed to encourage parents to collaborate with educators as partners in the academic, social, and emotional development of children. Much of this activity has centered on the provision of initiatives that support high-poverty parents or those whose children qualify for free and reduced-priced meals as a part of the National School Lunch Program. This program uses a federal funding formula to provide free or minimal-cost lunches for students whose families fall below a particular income threshold (U.S. Department of Agriculture, 2013). Federal policy such as NCLB presents a backdrop for educators who desire to implement activities in schools.

In the studied jurisdiction where this research was conducted, state code requires the board of education in any public school district to adopt policies promoting parent involvement, including strategies for helping parents support their children at school as well as at home. We suggest that this encouragement provides the authority for school districts and schools to develop substantive approaches to engage parents.

More recently, the endorsement of parent involvement through policies recommending the engagement of families in schools indicates that parent involvement in schools continues to be expected. This is evidenced by U.S. School Improvement Grants, U.S. School Turnaround initiatives, and U.S. Race to the Top programming, which suggest schools develop "strategies to effectively engage families and communities in supporting the academic success of their students" (Race to the Top, Executive Summary, 2009).

Parental involvement in schools: Outcomes and impact. The benefits of parent involvement in schools have been well documented in the literature. Scholars suggest that students perform better if parents are engaged in schools and advocating for children (Brantlinger, 2003; Epstein, 2011; Henderson \& Mapp, 2007; Sanders, 2008; Sheldon, 2003). Scholars also advance that stronger bonds between school and home reinforce the sense of community in both domains for children (Epstein, 2011; McNeal, 2015; Robinson, 2008). As illustrated by research, advantages attributed to parent involvement include: better school attendance and improved punctuality (McConnell \& Kubina, 2014; Sheldon, 2007), stronger performance in a child's academic habits and schoolwork (Deplanty, Coulter-Kern, \& Duchane, 2007; Wilder, 2014), and improved pro-social conduct (McCormick, Cappella, O’Connor \& McClowry, 2013; Robinson, 2008).

Despite the benefits of engaging parents, some studies of parental involvement in schools reveal disparities in levels of involvement depending upon geographic and socioeconomic context. Parents in rural and high-poverty areas, for example, may attend and support school activities such as family nights or athletic events, but are usually less engaged in decision-making opportunities (Bauch, 2011; Epstein, 2011). Middle-class families, on the other hand, typically have the human and social capital (i.e., time, political power) to be active in decision-making and policy-changing practices (Chrispeels, 2012; Rogers, Freelon, \& Terriquez, 2012).

Characteristics of rural and high-poverty families and communities. Despite research on rural schools and communities, no singular definition of "rural" exists. This presents an issue when scholars and practitioners attempt to address and advocate for greater supports and resources for rural contexts. As Semke and Sheridan (2012) reveal 
in their review of the literature on family-school partnerships in rural settings, some scholars describe rural communities in terms of population density and proximity to urban areas, while others define rural in terms of geography and types of settlement. Further, Semke and Sheridan advance that other theorists do not define rural at all. Howley and Howley (2000) contend that "rural regions have experienced different histories" that should compel scholars to expand the definitions of rural (p. 4). As such, it follows that conceptions of rural parents and how they approach their engagement also needs elaboration. This would suggest therefore that educational leaders, policy makers, and scholars should be mindful of the specific contexts, "place and culture" (Howley \& Howley, 2000), where rural parents are situated as they work to engage families in the school lives of children.

While definitions of "rural" vary by agency (Harmon \& Schafft, 2009), Budge (2006) proposes six common characteristics of rural places, including low population density, isolation, interdependence between community and school, regular out-migration of young people, and a strong attachment to place. These characteristics have been supported by others, who have noted that the geographic isolation of rural areas has led to a lack of job opportunities and, subsequently, severe poverty for many rural residents (Maynard \& Howley, 1997).

The distinctive features of rural communities pose unique challenges to developing rich and robust parent engagement in schools. Parents in rural communities are often preoccupied with sustaining their basic needs and thus have limited time and resources for extensive involvement in schools (Howley, Rhodes, \& Beall, 2009). Research has shown that those in rural communities typically have lower incomes proportionally than those in urban areas (Bauch, 2001; Howley \& Howley, 2010). Thus, individuals in rural areas tend not to have extensive assets to provide financial support to schools. Moreover, schools in rural settings are often under-resourced (Howley, Rhodes, \& Beall, 2009) placing schools in these contexts at a disadvantage due to "low wealth" (p. 519). As noted, parental skepticism (Howley, Rhodes, \& Beall, 2009) and the lack of trust between families and educators make it difficult for all parties to collaborate regarding the best interest for the students they share (Abrams \& Gibbs, 2000).

In their study of children enrolled in an urban Head Start Center, Fantuzzo, McWayne, Perry, and Childs (2004) found that home-based parent involvement behaviors - such as reading with one's child, implementing learning activities at home, or taking one's child into the community for learning opportunities-had a greater impact on students' achievement and pro-social behavior at school compared to school-based involvement strategies. This pattern, according to Fantuzzo et al., signals the need for schools to focus on developing parent involvement opportunities that support learning within the home environment. Importantly, however, Fantuzzo et al. also note that their findings may or may not be applicable to other populations, including rural families or families from various racial and ethnic groups; they suggest the need for more research to improve understandings of "the extent and nature of family involvement in early childhood education" (p. 478). As noted earlier, many parental involvement models have been patterned after conceptions of how middle-class parents engage with schools. They imagine school and home partnerships as relationships that can be easily facilitated by traditional models of activities and approaches used to connect parents to school organizations. This level of engagement of parents in the rural, high-poverty contexts can 
Navigating the Parent Involvement Terrain

be difficult to achieve or sustain as rural families grapple with identifying the capacity to be involved.

\section{Methodology}

Qualitative methods were used in this study to ascertain and analyze the perspectives of high-poverty rural parents as they engaged in the school lives of their children. This research investigates the complex nuances of the involvement of highpoverty and rural parents in the studied school district. Data for this study were gathered from parents in an Appalachian school district where parental views regarding involvement experiences in their children's school were observed. Specifically, the research team inquired about parent perspectives regarding the importance of parental involvement and their understandings of policies encouraging their participation in schools. In addition, their experiences in relation to Epstein's (2011) six strategies to involve parents in schools, the existence of social capital and social networks between parents as conceived by Bourdieu (1986), Horvat et al. (2003) and Lareau (2000, 2011), and parent perspectives of school culture and climate were examined.

\section{Participants}

Data were collected from a total of 16 parents/guardians at two selected elementary schools in the studied high-poverty, rural, Appalachian school district. Most of the participants interviewed were Caucasian Americans; two African American grandparents were also interviewed. In keeping with the identified demographics for the study, the majority of the parents were parents of high-poverty students based on the fact that their children were eligible for free and reduced lunch through the U.S. National School Lunch Program. The school principals assisted in the identification of parents to participate in the interview discussions, and the principals were aware that the research team was seeking parents who fit the category of high poverty.

Consistent with research, the mothers were more active than fathers in attending school meetings and participating in parent activities (Lareau, 2011), and out of the total interviews, four interviews were conducted with males and twelve were with females. As articulated in several of the discussions with the interviewees, many fathers were either working, not engaged in school activities, or absent in the lives of their children. The research team performed interviews during parent conferences, during a parent-teacher association (PTO) meeting, and at the end of a school day.

\section{Research Sites}

The research setting for this study involved two elementary schools in a highpoverty school district located in the Appalachian region of the United States. The Appalachian Regional Commission (ARC) defines Appalachia as a 205,000 square-mile region that follows the Appalachian Mountains from southern New York to northern Mississippi. Approximately 420 counties in 13 states are included in the region, resulting in a population that is politically, economically, and socially diverse. While some communities in Appalachia are considered urban (such as Pittsburgh, Pennsylvania), nearly $42 \%$ of the Appalachian population is rural - compared with $20 \%$ nationally (ARC, 2012). This rural geography contributes to severe economic poverty for many residents (Duncan, 1999; Pollard \& Jacobsen, 2015), who previously relied on extractive 
industries such as coal mining, forestry, and agriculture for their livelihoods and who currently struggle to find jobs in an increasingly trade- and service-oriented economy.

Tenwich and Montrose* are selected elementary schools in the studied school district. The schools are situated in a high-poverty school district in the rural Midwest. The studied schools are located in low-income, dense residential areas where most of the students and their families live in close proximity to the assigned school building. The poverty level in each of these schools is greater than $85 \%$ (School District superintendent report, 2014). Both schools are Title One eligible, based on the percentage of the students who are eligible for free and reduced-price lunch.

The schools are situated in a city of approximately 22,000 people, with almost $90 \%$ Caucasian and 10\% minority (U.S. Census Bureau, 2013). The median income in the community is roughly $\$ 35,000$, and almost a fourth of the population lives below the Federal poverty threshold as established by the U.S. Census Bureau. In considering the educational level of adults in the city, statistics show that less than $20 \%$ of the population has a college degree or higher (U.S. Census Bureau, 2013).

Access to the schools was achieved through an existing partnership between the district superintendent and the researchers' university. The superintendent served as a liaison between the researchers and two school principals who expressed an interest in participating in the study. The principals at each school site helped to identify and recruit parents for interviews.

\section{Data Collection}

This research project applied collective case study research methods (Stake, 2000), or a case study involving multiple locations, to fully ascertain parent views about their involvement in schools. Face-to-face individual and focus-group interviews were conducted in an effort to identify the true essence of the experiences of high poverty parents in a rural, Appalachian setting. A total of 16 parents participated in the interviews and focus groups, with some parents participating in both. Parent involvement initiatives within the studied district were compared against legislative guidance from current federal and state policy recommendations on engaging parents.

\section{Individual Interviews}

Individual interviews were used to observe and analyze the perspectives of parent participants in this research. The individual interviews were conducted in a semistructured format to allow for open-ended questions and to enable the interviewers to extract information that might be "moderately non-directive" (Fontana \& Frey, 2000). The interview protocol consisted of 26 interview questions organized into seven general sections. These interview categories included questions about parent views regarding their involvement levels, parent perceptions about policy encouragement for parent participation, their engagement experiences in Epstein's (2011) six categories of parental involvement, their social networks, and ideas about the school culture and climate. An assessment was made to ascertain what hindrances and opportunities existed in the involvement of parents in the school life of their children.

A total of seven face-to-face individual interviews were held at Tenwich and two individual interviews were held at Montrose. Each individual interview lasted approximately 30-45 minutes. 
Navigating the Parent Involvement Terrain

\section{Focus Group Interviews}

Focus groups of parents were used to help uncover diverse perspectives on parent involvement. This data collection approach was included in the study to augment the data gathered from the individual interviews and to "member check...developing understandings" (Glesne, 2011, p. 134). Focus groups were also held to lend opportunities for further elaboration by parents who, due to inhibitions, would be reluctant to share their perspectives. The researchers thus selected the focus group mode of inquiry to engage participants who potentially find one-on-one interviews intimidating (Madriz, 2000, p. 835). As Glesne (2011) notes, "focus group research can also have emancipatory qualities if the topic is such that the discussion gives voice to silenced experiences" (p. 134). The focus group setting appeared to provide a venue that parents were comfortable with, given their openness during the group discussion.

A total of two focus group interviews were conducted, one at each studied school. The criteria for selecting the parents included: their children were eligible for free or reduced lunches, received Title One services, and the parents were available at the school at the time of the interviews. There were four parents who participated in the focus group at Tenwich school and three parents who participated in the focus group at Montrose school. In the case of Tenwich, parents who were attending a parent-teacher organization meeting and who met the criteria for our study were invited to stay after the meeting to participate in a focus group session. At Montrose, the principal assembled a group of parents who met the criteria. Each focus group interview lasted about ninety minutes.

Theorists note that often in focus groups certain individuals have the potential to dominate conversations (Patton, 2002, p. 387). These outspoken parents can cause other parents to be inhibited from speaking (Patton). This was evidenced at Tenwich where one of the participants, a new parent to the school community, barely spoke during the focus group session. By contrast, two other parents, both officers in the parent-teacher organization, dominated the conversation and overshadowed the opinions of others.

\section{Data Analysis}

Data gathered from the individual and focus group sessions were recorded, transcribed, and coded by the researchers in an attempt to extract common themes and patterns. Verbatim transcription of the audio interviews was loaded into the qualitative data analysis software MAXQDA, which was then used to assist in the data analysis process. Each individual interview was treated as a case and coded using emergent, in vivo, and a priori codes that related to the research questions. The researchers organized the interview data into emergent thematic categories using codes. We used these emergent data and categorical themes as the primary vehicle for analys is of the data.

\section{Findings}

Based on our interviews, several themes emerged in the data collected. Overall parental perceptions were reflective as these stakeholders considered varied aspects of the school culture and climate. These views from the studied parents suggest that there are contextual nuances that impact the experiences of parents in the respective school buildings. In Tenwich School, the principal was new and many parental involvement affairs were forwarded to the parent-teacher organization. The parent-teacher 
organization was made up of a handful of parents who attended consistently. Other parents were invited to attend meetings, but it appeared that there was not great energy put into membership building. Based on the principal deferment of parental issues to the parent-teacher organization, the influence of an already existing network of parents who were parent-teacher organization participants was apparent. At Montrose School, the principal was more established and seemingly more laidback about affairs related to parent involvement. This principal appeared to be focused on academic priorities, and while she was conscious of the needs of parents, she also seemed to defer activities related to parents to the parent-teacher organization with little oversight.

Given the individual and focus-group interviews from the research, the following recurrent themes were discussed repeatedly by the participants. Major topics and emerging narratives include motivation for involvement, time constraints, and within group marginalization. Further elaboration regarding these themes and patterns is found below.

\section{Motivation for Involvement}

The studied parents provided a variety of reasons for their involvement in the affairs of the school, even though almost all parents identified a connection between their degree of involvement and their child's academic success. Several parents explained that they were involved in order to visibly demonstrate their support and encouragement to their children. One parent advanced that, "It shows her that she can count on me for most of the things in her life. With me helping her, then it will encourage her to want to do better" (Deanna at Tenwich).

Another parent connected parental participation with the academic engagement of their child and noted "A parent's involvement - you're only going get as much education as your parents' involvement ... If they're going to school and doing other things, then it's my duty to make sure, as a parent, that I reinforce - you're here for an education" (Stacy at Tenwich). These sentiments were echoed by yet other parents and one underscored the importance of involvement by saying, "Everybody has stuff going on, but to be there for the kids, it makes a lot of difference" (Bethany at Montrose)

Interview transcripts revealed that a number of parents saw involvement as a way to be informed about what was happening at the school and to establish direct contact with faculty and staff. Others described involvement as a way to build rapport with other parents and students or to show their commitment and support to their children. Many parents believed that their involvement was a way for them to stay informed about school affairs. "I don't want to be blindsided by experiences that he has that I know nothing about it" (Matt at Tenwich).

A few parents were involved in schools out of necessity, seeing their engagement in schools as a necessity for their child's health and wellness. In a remark by a mother whose son's medical needs required her to be at the school regularly, she concluded that: "My son is a diabetic. I know that it's going to take him extra time to get up to where the other children are. That's why I'm working with the teacher on a daily basis to get him up there, or to keep him up there, to where he needs to be to move on and not left behind" (Audrey at Tenwich). Overall, parents in the selected schools appeared to care about their children and view their involvement as important. 
Navigating the Parent Involvement Terrain

\section{Time}

The element of time was continually mentioned as a theme by parents in the interview transcripts. Many commented on the importance of parental involvement in the school life of their children but lamented that constraints on their time made it difficult for them to participate at desired levels. Some parents remarked that they wished they could allocate a greater complement of time to being involved in school activities with their children, but they were not able. Common responses by parents were similar to the following: "The only thing that would keep me from [participating] would be my job, and work, because I work late nights, 12-hour split for the most part" (Lisa at Montrose) Yet another parent noted that they would like to participate at a greater level, but their involvement is "Not as much as I'd like to because I work and I'm going to school full time. Right now, my involvement is very low (Pamela at Montrose)." Work demands again appeared to inhibit parental engagement when a parent stated, "[I don't participate] as much as I would like because I work and my kids play sports. There isn't really enough time to do anything" (Bruce at Tenwich).

These parental concerns are consistent with the perspectives of scholars who note that rural parents express concerns about issues that they have in scheduling and finding time to be involved (Kushman \& Barnhardt, 2001; Semke \& Sheridan, 2012). To encourage more participation among parents, some participants suggested that they would like to see the school offer activities at varied times, such as in the evenings so that they could participate more. They advanced that additional parents might be inclined to be engaged in school activities if they had greater options for participation.

\section{In-group Marginalization}

Parent comments from the interviews suggested that active parents distanced themselves from inactive parents and hierarchized themselves according to their levels of involvement. In interview and focus-group conversations, parents never uttered the term "marginalization," but its practice was implied in their conversations. A group of parentteacher organization parents from Tenwich highlighted that their involvement in the schools was an example of their active involvement and engagement, a sentiment illustrated by comments such as "Those of us here, we kind of built out lives around being able to be here" and "Of the 300 parents that are [at this school], it's the people at this table that believe in participation (Holly at Tenwich)" Remarks made by the parents at the parent teacher association (active parents) suggested that the active parents thought of themselves as being better than the other parents (inactive parents), who are perceived as being chronically absent from parent-teacher conferences, and who rarely show up for activities at the school: "School's just free babysitting for a lot of the people that are here because they either don't care to parent their kids or they're too busy just trying to feed and clothe their kids that this is what school is. It's free daycare (Stacy at Tenwich)."

A narrative of parents marginalizing other parents unfolded as the research team conducted the study. First, active parents appeared to use their active presence in the school to overcome the stigma attached to being an absent parent (almost expressing their involvement as an act of being a good parent and a good citizen). To further illustrate parent sentiments about being active, a parent at Tenwich school suggested the following: "If you're not involved in your kid's education, then you're pretty much not involved" (Stacy at Tenwich). Active parents seem to connect the absence of other parents with 
poor parenting and lack of concern by parents who were not engaged. They also attributed lack of involvement by inactive parents to negative behavior. One parent, for example, emphasized the poor hygiene of children whose parents are inactive in school:

these little kids ... their clothes are filthy, they don't fit. Their hair is in just a knot on the top of their head. It's obviously not been brushed for a month, let alone washed. They just smile at you. You want to hug them, but you don't want to catch something.(Holly at Tenwich)

Second, active parents seemed to want to highlight their acts of involvement and to distance themselves from the inactive parents who are usually missing from many school activities. Third, when blaming the inactive parents as problem parents, active parents perceived that the absence of inactive parents is tantamount to acts of negligence towards their children: "It seems to be something with this town that there is just grandma/grandpa stuff, great-grandma and grandpa stuff raising the kids, and they're just out doing whatever they want to do. I'm like, 'What is wrong with you people?' I don't understand" (Holly at Tenwich).

\section{Discussion}

\section{Parent Involvement Policies and Practices at Tenwich and Montrose}

Our first research question sought to understand how the studied school district responded to state and federal mandates requiring parent participation in schools. The researched school district and school websites exhibited compliance with elements of Title One and NCLB by sharing information with parents regarding student, school, and district performance. School and district websites contained links with content regarding ways for parents to get involved and also provided information about school and district related activities. However, several parents noted that not all families have access to computers in order to retrieve information on the Internet. This circumstance posed a problem with the school and district's use of the Internet as a communication vehicle.

In the participant interviews, most parents noted that educators in the schools often provided information for students to take home to their parents. "Normally we get a bunch of flyers and informational paperwork from them [educators] stating 'hey we have this, you can participate in this' We normally get alotta information from the school as far as parent teacher involvement or parent involvement" (Deanna, at Tenwich).

Although information about the schools and activities seemed to be available, parents still expressed some uncertainty regarding how to be fully involved in the school life of their children. Even those parents who attended the parent conferences shared comments that indicated they were unsure about getting involved.

\section{Parents' Perceptions of their Participation Experiences}

Our second research question was intended to ascertain parents' personal experiences with involvement at the school. Through our interviews with parents, two primary themes emerged in response to this question: 1) parents were motivated to be involved because they attributed their participation to positive behavioral and academic outcomes for their children, and 2) parents lamented that work and other obligations often prevented them from being as involved as they wanted to be. A number of parents 
Navigating the Parent Involvement Terrain

indicated that they believed it was key for them to support their children to encourage their children that school was important.

Parents also noted issues regarding limited time to be engaged, and that it posed various problems. During the interviews many parents noted that they wanted to participate more in the school life of their children, but jobs or other conflicts made it difficult for them to be present. Suggestions emerged from parents regarding alternative times that school activities might take place, particularly since most of the events at the school occurred immediately following the school day.

\section{Assets and Barriers to Parent Participation}

Our third research question aimed to examine the specific hindrances or opportunities that exist for parents to be engaged in the school life of their children. As previously demonstrated by Smrekar and Cohen-Vogel (2001), there was a marked difference for participants in this study between parents who regularly participated in school activities and those who did not. Active or engaged parents were those who, despite the limitations of their schedules, made time to volunteer at the school, attend conferences, or participate in parent-teacher organization meetings. Parents whose presence at the school was less evident were perceived by other parents as not caring about their children, a perception that was reinforced by the physical appearance of some children whose "filthy appearance" was interpreted as a sign that they were less cared for by their guardians (Holly, at Tenwich). Arguably, then, active parents appeared to absolve themselves from being marginalized, by shifting bad parenting behavior to other parents. Based on the comments of the parent-teacher organization president and others at the meeting, one can conclude that active parents appeared to have created a class of their own to demonstrate deviation from the stereotype of marginalized. The research team concludes that the absence of the inactive parents from school activities is a form of voicelessness.

Conclusions about voicelessness are based on the marginalizing attitudes of active parents and also the fact that they do not have an opportunity to share their perspectives. In their study of low-income minority parents, Smrekar and Cohen-Vogel (2001) also found that parents who participated frequently in school activities criticized or disparaged parents who were not engaged. Additionally, there were many dynamics involved with parent participation in the parent-teacher organization that seemed to be intricately involved with engaging parents in school activities and affairs. The marginalization that the researchers observed by active parents against inactive parents is consistent with the reflections of varied authors regarding parent-teacher organization involvement and monitoring (Kroeger, 2014; Lee \& Bowen, 2006; McNeal Jr., 1999). These authors note that parent-teacher organizations often appear to advantage European American or middle-class parents more than minority (African American or Hispanics and Asian American) parents and those from high-poverty groups. Participants in the Tenwich parent-teacher organization are perceived to be pitying or looking down their noses at parents who they considered high poverty or low socioeconomic status. These same parent attitudes were less apparent at Montrose. 


\section{Conclusion}

"Family" usually connotes a positive meaning, including the concept of togetherness among people, affectionate relationships with kin, and emotional solidarity in times of crisis. Within the context of this study, however, a pattern emerged where parent involvement in school was used by parents as a criterion for evaluating other people's conceptions of family. One parent, for example, equated low parent participation with 'the decline of the family unit as a whole... I honestly just think the parents don't care. They're too busy doing their own thing that the kids are just lost in the mess" (Stacy at Tenwich). For active parents, then, it appears that concept of family is embedded in the enactment of behaviors where they perceive themselves as "the good or active parent," prioritizing their children's education to the point of making regular appearances at the school to interact with teachers, school staff, and other parents. The active parent demonstrates his or her family values by actively supporting and encouraging his/her child in school; support and encouragement that takes the form of volunteering time to school activities, donating supplies for school projects, and responding to solicitations from the parent-teacher organization. Active parents position themselves in opposition to inactive parents who are less visible at the school. These parents are perceived as being "lazy" and as not caring about the wellbeing of their children (Holly at Tenwich). In the minds of those who consider themselves active parents, the inactive parents are construed as anti-family. Yet, it may be the case that for seemingly inactive parents, "family" is defined as working multiple jobs to maintain financial stability, or relying on extended kinship networks to take care of school-related business. Consistent with the theme of the voicelessness that emerged in our data, the voices of these parents are absent from our analysis - and, so too, are they often silenced by traditional models of parent engagement.

In light of the research findings, several themes have emerged as conclusions in the context of the research questions and as a suggested direction for researchers, educators and school leaders. Based on this research project, the data and the findings suggest ideas regarding a way forward for educational practitioners and researchers. Implications from our study reveal that there are parents who never engage with schools or interact with active parents regarding the school lives of their children. We advance that absent parents still need to be identified and interviewed, to include their ideas regarding ways that they might be involved. It might be appropriate for strategies to be developed and approaches considered both by school professionals and parents on how to reach out to absent parents and motivate them to share their concerns and ideas. Further, this extra effort by educators and active parents might encourage inactive parents to ultimately interact with schools and parent groups. Administrators and teachers can be key in identifying and reaching out to parents who are not present. Given the relationships of educators with student families and the formal authority that school personnel command, it is possible that educational professionals be conduits for full dialog with non-engaged parents.

As suggested, another major observation in the data showed that hierarchies seemed to exist within groups of high-poverty parents who form opinions about parents who are not present. To create greater understandings between parents and to minimize alienation that may occur amongst the parent population, school staff should work with parent leaders to develop greater receptivity to parents who are not consistently involved with schools. It might be productive for the parent-teacher organization and involved 
parents to collaborate with school personnel on strategies to engage parents who are not present. Teachers and administrators can be key in identifying parents who are inactive in schools. Given their relationships and the formal authority that these school leaders command, they could serve as conduits for full dialog with absent parents. As a further effort, teacher and administrator perspectives on the engagement of parents should be solicited to get a variety of views about different school stakeholders and approaches that might be used to draw them to become involved

It is clear that typical models and frameworks of parental involvement are often not appropriate for rural and high-poverty settings and that alternative, innovative approaches might be more effective. The engagement of parents and families in schools might benefit from a more contextual approach to school-home partnerships. Traditional parental involvement models could benefit from an overhaul regarding how school and family partnerships are cultivated for rural and high-poverty situations. Given that rich relationships flourish (Pushor, 2010; Tschannen Moran, 2014), teachers' knowledge about their students could provide ideas and initiate plans to involve students' families. Teachers and educational leaders could subsequently develop a road map to be used to engage the students' families around areas of common interest. School personnel could reach out to families so that parties from school and home can collaboratively develop a full engagement plan. 


\section{References}

Abrams, L. S., \& Gibbs, J. T. (2000). Planning for school change school-community collaboration in a full-service elementary school. Urban Education, 35(1), 79-103.

Appalachian Regional Commission. (2012). The Appalachian region. Retrieved from http://www.arc.gov/appalachian_region/TheAppalachianRegion.asp

Auerbach, S. (2012). Conceptualizing leadership for authentic partnerships: A continuum to inspire practice. In S. Auerbach (Ed.), School leadership for authentic family and community partnerships: Research perspectives for transforming practice (pp. 29-51). New York, NY: Routledge.

Bauch, P. A. (2001). School-community partnerships in rural schools: Leadership, renewal, and a sense of place. Peabody Journal of Education, 76(2), 204-221.

Bourdieu, P. (1986). The three forms of capital. In J. G. Richardson (Ed.) Handbook of theory and research for the sociology of education. New York: Greenwood Press.

Brantlinger, E. A. (2003). Dividing classes: How the middle class negotiates and justifies advantage. New York, NY: Routledge Palmer.

Budge, K. (2006). Rural leaders, rural places: Problem, privilege, and possibility. Journal of Research in Rural Education, 21(13), 1-10.

Catawba School District Superintendent Report (2014).

Chrispeels, J. H. (2012). Parents as action learners and leaders: Lessons for administrators in working with families and intermediary organizations. In S. Auerbach (Ed.), School leadership for authentic family and community partnerships: Research perspectives for transforming practice (pp. 151-172). New York, NY: Routledge.

Deplanty, J., Coulter- Kern, R., and Duchane, K. A. (2007). Perceptions of Parent Involvement in Academic Achievement. The Journal of Educational Research $100,(6)$

Dewey, J. (1910). How we think. Boston: D.C. Heath \& Co.

Dewey, J. (1916). Democracy and education: An introduction to the philosophy of education. New York: Macmillan.

Duncan, C. M. (1999). Worlds apart: Why poverty persists in rural America. New Haven, CT: Yale University Press. 
Navigating the Parent Involvement Terrain

Eccles, J. S., \& Harold, R. D. (1996). Family involvement in children's and adolescents' schooling. In A. Booth \& J. F. Dunn (Eds.), Family-school links: How do they affect educational outcomes (pp. 3-33). Mahwah, NJ: Erlbaum.

Epstein, J. L. (2011). School, family \& community partnerships: Preparing educators \& improving schools. Boulder, CO: Westview Press.

Fontana, A., and Frey, J. H. (2000). The interview: From structured questions to negotiated text. In Norman Denzin and Yvonna Lincoln, The Handbook of Qualitative Research, Thousand Oaks: Sage, 2003, 645-672.

Glesne, C. (2011). Becoming qualitative researchers: An introduction (4th ed.). Boston, MA: Allyn \& Bacon.

Harmon, H. L., \& Schafft, K. (2009). Rural school leadership for collaborative community development. The Rural Educator, 30(3), 4-9.

Henderson, A. T., \& Mapp, K. L. (2002). A new wave of evidence: The impact of school, family, and community connections on student achievement. Austin, TX: Southwest Educational Development Laboratory.

Horvat, E. M., Lareau, A., \& Weininger E. B (2003). From social ties to social capital: Class differences and relations between schools and parent networks. American Educational Researchers Journal, 40(2), 319-351.

Howley, A., Bickel, R., \& McDonough, M. (1997). The call for parent involvement in rural communities: Mantra or mystification. Journal of Research in Rural Education, 13(2), 101-107.

Howley, C., \& Howley, A. (2010). Poverty and school achievement in rural communities: A social-class interpretation. Rural education for the twenty-first century: Identity, place, and community in a globalizing world, 34-50.

Howley, A., Rhodes, M., \& Beall, J. (2009). Challenges facing rural schools: Implications for gifted students. Journal for Education of the Gifted, 32(4), 515536.

Kroeger, J. (2014). Where do we go from here in family engagement? Comments at the late turn of the 21st century. Journal of Family Diversity in Education, 1(1), 1-20.

Larson, W., \& Howley, A. (2006). Leadership of mathematics reform: The role of high school principals in rural schools. ACCLAIM Monograph, (3).

Lareau, A. (2011). Unequal childhoods: Class, race and family life. Berkley, CA: University of California Press. 
Lareau, A. (2000). Home advantage: Social class and parental intervention in elementary education. Lanham, MD: Rowman \& Littlefield Publishers.

Lin, N., Cook, R. S., Burt, K. S. (Eds.) (2001). Social capital: Theory and research. New Brunswick, NJ: Transaction Publishers.

Lee, J. S., \& Bowen, N. K. (2006). Parent involvement, cultural capital, and the achievement gap among elementary school children. American Educational Research Journal, 43(2), 193-218.

Lightfoot, S. L. (2004). The essential conversation: What parents and teachers can learn from each other. New York, NY: Ballantine Books.

Mckenna, \& Millen (2013). Look! Listen! and Learn! Parent narratives and ground theory models of parent voice, presence and engagement in K-12 education. School Community Journal, 23(1) 9-48.

McNeal, R. B. (1999). Parental involvement as social capital: Differential effectiveness on science achievement, truancy, and dropping out. Social Forces, 78(1), 117144.

Madriz, E. (2000). Focus groups in feminist research. In N. Denzin and Y. Lincoln (Eds.), The Handbook of Qualitative Research, Thousand Oaks: Sage, pp. 835850.

Maynard, S., \& Howley, A. (1997). Parent and community involvement in rural schools. ERIC Clearinghouse. Retrieved from http://files.eric.ed.gov/fulltext/ED408143.pdf

McConnell, B. M., \& Kubina, R. M. (2014). Connecting with families to improve students' school attendance: A review of the literature. Preventing School Failure, 58(4), 249-256. doi: 10.1080/1045988X.2013.821649

McCormick, M. P., Cappella, E., O’Conor, E. E., \& McClowry, S. G. (2013). Parent involvement, emotional support, and behavior problems: An ecological approach. The Elementary School Journal, 114, 277-300.

McDermott, P., \& Rothenburg, J. J. (2000). Why urban parents resist involvement in their children's elementary education. The Qualitative Report, 5(3), 1-16.

McNeal, R. B. (2015). Parent involvement and student performance: the influence of school context. Educational Research Policy and Practice, 14, 153-167.

No Child Left Behind Act of 2001, 20 U.S.C. $\S \S 6301$ et. seq (2002).

No Child Left Behind Act of 2001, 20 U.S.C. $\$ \$ 6516$ et. seq (2002). 
Navigating the Parent Involvement Terrain

O'Connor, S. (2001). Voices of parents and teachers in a poor, White urban school. Journal of Education for Students Placed At Risk, 6, 175-198.

Patton, M. Q. (2002). Qualitative research and evaluation methods. Thousand Oaks: Sage Publications, Inc.

Pollard, K. \& Jacobsen, L. A. (2015). The Appalachian region: A data overview from the 2009-2013 American Community Survey. Retrieved from http://www.arc.gov/as sets/research_reports/DataO verviewfrom20092013ACS.pdf

Plunkett, S. W., \& Bamaca-Gomez, M. Y. (2003). The relationship between parenting, acculturation, and adolescent academics in Mexican-origin immigrant families in Los Angeles. Hispanic Journal of Behavioral Sciences, 25, 222-239.

Pushor, D. (2010). Are schools doing enough to learn about families? In M. M. Marsh, \& T. Turner-Vorbeck (Eds.), (Mis) Understanding families: Learning from real families in our schools (pp.4-16). New York: Teachers College Press.

Robinson, D. V. (2008). The engagement of low income and minority parents in schools since No Child Left Behind: Intersections of policy, parent involvement and social capital. Unpublished doctoral dissertation: The Ohio State University.

Rogers, J., Freelon, R., \& Terriquez, V. (2012). Enlisting collective help: Urban principals' encouragement of parent participation in school decision-making. In S. Auerbach (Ed.), School leadership for authentic family and community partnerships: Research perspectives for transforming practice (pp. 53-77). New York, NY: Routledge.

Sanders, M. (2008). How parent liaisons can bridge the home school gap. Journal of Educational Research. 100(5), 287-298.

Semke, C. A., \& Sheridan, S. M. (2012). Family-school connections in rural educational settings: A Systematic review of the empirical literature. School Community Journal, 22(1), 21-47.

Schafft, K. A., Alter, T. R., \& Bridger, J. (2006). Bringing the community along: A case study of a school district's information technology rural development initiative. The Journal of Research in Rural Education, 21(8), 1-10.

Sheldon, S. B. (2003). Improving student attendance with school, family, and community partnerships. Urban Review, 35(2), 149-165.

Sheldon, S. B. (2007). Improving student attendance with school, family, and community partnerships. Journal of Educational Research, 100, 267-275. 
Sheldon, S. B. \& Epstein, J. L. (2005a). Involvement counts: Family and community partnerships and math achievement. Journal of Educational Research, 98(4): 196206.

Smrekar, C., \& Cohen-Vogel, L. (2001). The voices of parents: Rethinking the intersection of family and school. Peabody Journal of Education, 76(2), 75-100.

Tschannen-Moran, M. (2014). Trust matters: Leadership for successful schools. John Wiley and Sons.

U.S. Census Bureau, (2013). Retrieved from: http:/quickfacts.census.gov/qfd/states/

U.S. Department of Agriculture. (2013). National school lunch program factsheet. Retrieved from: http://www.fns.usda.gov/sites/default/files/NSLPFactSheet.pdf

U.S. Department of Education (2001). Public Law 107-110, "No Child Left Behind Act of 2001". Part A - Improving Basic Programs Operated by Local Educational Agencies. Retrieved from http://www.ed.gov/policy/elsec/leg/esea02/pg2.html\#sec1112.

U.S. Department of Education (2009). Race to the Top: Executive Summary https://www2.ed.gov/programs/race tothetop/executive-summary.pdf

Van Velsor, P., \& Orozco, G. L. (2007). Involving low-income parents in the schools: Community centric strategies for school counselors. Professional School Counseling, 11, 17-24.

Wilder, S. (2014). Effects of parental involvement on academic achievement: A metasynthesis. Educational Review, 66(3), 377-397. doi:

10.1080/00131911.2013.780009

\section{Notes}

* Pseudonyms assigned to the studied schools 